\title{
Haftungsrecht und Entschädigungsfonds
}

\author{
Eine Untersuchung zum deutschen und französischen Recht
}

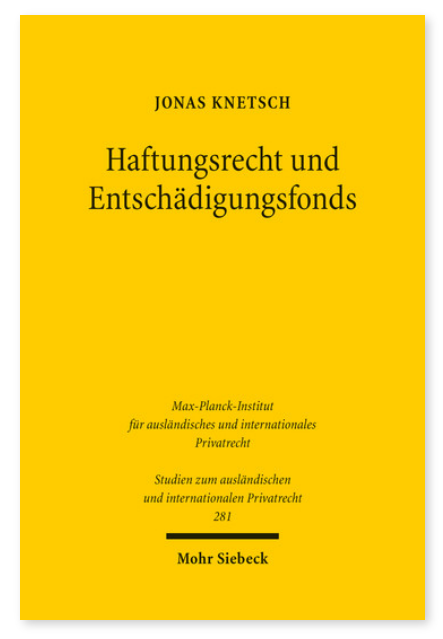

2012. XXIII, 257 Seiten. StudIPR 281

ISBN 978-3-16-152165-2

DOI 10.1628/978-3-16-152165-2

eBook PDF $69,00 €$

ISBN 978-3-16-151952-9

fadengeheftete Broschur 69,00€
Die sozialen und technologischen Umwälzungen der Moderne stellen das heutige Schadensausgleichsrecht vor große Herausforderungen. Zu deren Bewältigung ist das Recht des Schadensersatzes seit dem Beginn des 20. Jahrhunderts um alternative Kompensationsmechanismen ergänzt worden. Neben der Privatversicherung und den sozialen Sicherungssystemen haben in den letzten Jahrzehnten insbesondere Entschädigungsfonds an Bedeutung gewonnen. Jonas Knetsch widmet sich der systematischen Aufarbeitung dieser neuartigen Schadensabnahmesysteme sowie deren Einordnung in das bestehende Entschädigungsrecht. Da Fondslösungen in der Diskussion über die Fortbildung des Schadensausgleichsrechts bisher wenig Beachtung gefunden haben, erörtert er unter Berücksichtigung der Erfahrungen aus dem französischen Recht die Perspektiven derartiger Einrichtungen für die zukünftige Bewältigung komplexer Schadenstypen. Die Arbeit wurde mit dem CBH-Dissertationspreis der Rechtswissenschaftlichen Fakultät der Universität zu Köln ausgezeichnet.

Jonas Knetsch Geboren 1982; Studium der Rechtswissenschaften in Köln und Paris; 2011 Promotion zum Dr. iur. und zum Docteur en droit; seit 2012 Maître de conférences am Institut für Rechtsvergleichung der Université Panthéon-Assas (Paris II).

Jetzt bestellen:

https://mohrsiebeck.com/buch/haftungsrecht-und-entschaedigungsfonds-9783161521652?no_cache=1 order@mohrsiebeck.com

Telefon: +49 (0)7071-923-17

Telefax: $+49(0) 7071-51104$ 